\title{
A Study on Quality-of-Life Perception of Informal Employment in Urban Tourism
}

\author{
Jiajia $\mathrm{Xu}^{1, *}$ \\ ${ }^{1}$ Fuzhou University of International Studies and Trade, Fuzhou, Fujian, China \\ *Corresponding author. Email: selenexu185@gmail.com
}

\begin{abstract}
In previous studies on the impact of tourism development on the quality of life of urban residents, it is difficult to reduce the interference of non-tourism factors and highlight the direct effect of tourism on the quality of life by treating urban residents as homogeneous groups. Taking five scenic spots in Fuzhou City as example, this paper focuses on the informal tourism employees among residents. Through the analysis of 151 convenience and snowball samples, it studies the composition of their quality of life, and compares the differences in the quality of life of different employees. The results show that, different from other residents, tourism informal employees pay more attention to leisure and entertainment, work prospects, family life, work status, social communication, consumption and safety, ability development and living conditions, accounting for 58.3\%. In areas where interpretation is large, happiness is generally low. The study further shows that the well-being of employed people with different demographic characteristics and employment conditions is not different in most areas of quality of life, their overall well-being is highly similar, and their well-being is at a medium level.
\end{abstract}

Keywords: Informal employment, Quality of life, Subjective well-being, Urban tourism, Fuzhou.

\section{INTRODUCTION}

Because the role of cities in tourism development is becoming more and more important (Liang \& Hui, 2016), the impact of tourism development on the life of urban community residents has attracted much attention, becoming the main topic of tourism impact research, involving economic impact (R.Hoy, 1980), social and cultural impact (Stylidis, Biran, Sit, \& Szivas, 2014), environmental impact and so on. Meanwhile, tourism development is the focus of many cities to promote economic growth, employment of residents to achieve tourism poverty reduction (Ashley, 2010), tourism poverty alleviation, and its fundamental purpose is to improve the quality of life of residents. During recent years, some scholars have tried to reveal the relationship between tourism development and the quality of life of urban residents, and carried out case study (Nawijn \& Mitas, 2011) and theoretical discussion in some countries and regions (Buzinde, Kalavar, \& Melubo, 2014). However, the above studies generally regard residents as homogeneous groups, and do not subdivide the residents themselves. Studies such as Andereck have shown that residents who are engaged in tourism employment and often contact tourists perceive the impact of tourism on their quality of life more strongly than other residents (Andereck \& Nyaupane, 2010). Obviously, it is not only difficult to reduce the interference of other non-tourism factors (Liang \& Hui, 2016), but also difficult to highlight the direct effect of tourism on quality of life. This paper focuses on tourism informal employment among urban residents. As the real participants and beneficiaries of tourism development, their employment mobility and income instability are (Kim, Uysal, \& Sirgy, 2013), and their quality of life is closely related to tourism. Studying this group can capture the core relationship between tourism and quality of life. Therefore, this paper takes the tourism informal employment of five urban scenic spots in Fuzhou as the object, studies the main components of their quality of life, and discusses the differences in the quality of life of the employed people with different social and demographic characteristics and employment conditions. 


\section{STUDY ON THE QUALITY OF LIFE OF NON-REGULAR WORKERS IN TOURISM}

\subsection{Quality of Life of Informal Employment in Tourism and Its Influencing Factors}

The study of quality of life is different from the previous study on residents' attitude to tourism development (Marcouiller, 2016). Allen believes that attitude or impact studies focus on residents' perception of the impact of tourism on the community or the environment, while the quality of life is specific to the impact of the above effects on various major areas of personal or family life (Allen, 2018). By nature, the effects include positive and negative. The positive effects are related to environmental improvement, land appreciation, matching optimization, abundant facilities increase, etc. The negative impact includes congestion, environmental pollution, garbage increase, public security deterioration and traffic problems (Ap, 1992). To the extent, the cognitive elements of SWB and life satisfaction rather than emotional elements (affective component of SWB) of subjective well-being are the most affected by tourism (Maslow, 1959). The emotional elements are mainly affected by shortterm common events (daily happenings), not longterm continuous life areas. According to some studies, the areas of quality of life most affected by tourism are mainly those related to communities or cities, such as security, environment, image, transportation, public services, greening, infrastructure, health, etc., while other areas of quality (Andereck \& Nyaupane, 2010) life have less impact. Kim and so on further point out that the main areas of quality of life and the specific aspects of tourism impact are corresponding, such as positive tourism economic benefits will improve the residents' perception of quality of life in the material field (Kim et al., 2013). A study targeting residents of two communities in Tanzania found that different communities, age groups, and gender groups are not concerned with the same areas of life, while tourism has a different impact on each area (McCabe \& Johnson, 2013). For example, older men focus on livestock, children and wives; young men on money, livestock and children; and women on children and livestock (Buzinde et al., 2014).

There are many factors affecting community residents' attitude and quality of life evaluation, and there are differences between groups (Meier \& Schäfer, 2018). These factors include general demographic characteristics such as gender, age, income, education, occupation, etc. (Andereck \& Nyaupane, 2010), as well as resident years of residence, place of birth, and mobility characteristics (Moscardo, Konovalov, Murphy, \& McGehee, 2013). At the same time, the employment situation is also an important factor (Andereck \& Nyaupane, 2010). People engaged in tourism employment or those dependent on tourism life feel the impact of tourism more strongly than other residents (J.E.Brougham, 1981). Moreover, the (Lankford, 2016) degree of residents' understanding of tourism situation, the degree of participation in tourism development decisions (Lankford, 2016) and the frequent degree of contact with tourists (Brougham, 1981) are all important influencing factors. In recent years, the informal employment of tourism is gradually paid attention to by domestic scholars (Cukier, 1994), which is usually included in the discussion of tourism employment related to tourism impact (Wahnschafft, 1982) and tourism poverty reduction (Boonsiritomachai \& Phonthanukitithaworn, 2019). People engaged in informal tourism employment may be a lifestyle choice in addition to subsistence. Income differentiation of practitioners is obvious, not all low-income people, but also "high-income" (Ulleberg \& Rundmo, 2003). This shows that the tourism informal employment group is not limited to meet the survival needs, but also to pursue the quality of life (Mohotti, Jayawardena, \& Teare, 2013). Because tourism informal employment generally has the characteristics of small scale, low input, low technology, low organization and so on low threshold, not decent (Westman \& Eden, 1997), the instability of work directly leads to income instability, which may further affect the quality of life (Mohseni, Jayashree, Rezaei, Kasim, \& Okumus, 2018). Therefore, in the study of the quality of life, it is necessary to focus on their employment status, including working years, daily working hours, employment investment, employment status and so on.

\subsection{Construction of a Measurement Scale for the Quality of Life of Non-regular Workers in Tourism}

There are two models for quality of life measurement: one is the Scandinavian model that emphasizes objective indicators, using a set of social indicators that are independent of individual evaluation, such as life expectancy, crime rate, 
unemployment rate, GDP, poverty rate, etc. (Bauer, 1960); the other is the American model that focuses on subjective indicators, mainly using subjective well-being (McCabe \& Johnson, 2013), life satisfaction (Caunt, Franklin, Brodaty, \& Brodaty, 2012), happiness index (Caunt et al., 2012) or good life (Vittersø, Oelmann, \& Wang, 2007) individual subjective assessment scales of social conditions. To synthesize the advantages of the subjective and objective model, Veenhoven proposed a concise welfare index (summary welfare indices) (Vitters $\varnothing$ et al., 2007). Cummins proposed the total quality of life scale, which also involved the subjective and objective evaluation of the material welfare, health, productivity, intimacy, safety, community and emotional health and other seven quality of life (Bimonte \& Faralla, 2014). Zhou Changcheng and others are divided into eight fields according to the actual situation of China: work status, family and social relations, leisure and entertainment, health status, material consumption and ownership, selfdevelopment, public service, public policy (ChangCheng, 2008). In tourism research, scholars only explore areas closely related to tourism. The tourism quality of life model (TQOL) constructed by Andereck includes community welfare, urban problems, lifestyle, community identity, natural and cultural protection, economic development, leisure and entertainment, criminal behavior and other eight fields (Andereck \& Nyaupane, 2010).

The above studies basically refer to the classical scale of quality of life and adjust the scale according to the specific conditions of the subjects in order to construct a new scale suitable for the research problems. This paper studies the tourism informal employment, in addition to the quality-oflife dimension of the general tourist destination residents, but also need to consider the special dimensions of tourism informal employment, such as work conditions. Therefore, this paper takes the scales of Zhou Changcheng et al. (2008) and Guo Yingzhi et al. (2007) as the core, and refers to Nawijn and Mitas (2011) and Andereck and Nyaupane (2010) to constructed a subjective wellbeing scale with 31 indicators in 8 fields, involving 8 fields of family life, social communication, health status, self-development, work status, leisure and entertainment, material consumption and public service. Using Likert 7-point scale (1 very disagree $\sim 7$ very agree).

\section{RESEARCH DESIGN}

The informal sector of tourism refers to smallscale units engaged in tourism goods and services without government registration, mainly composed of independent workers, street traders and selfemployed persons. Non-standard employment in the tourism formal sector refers to temporary workers, seasonal workers, interns and other flexible temporary workers working in tourism formal enterprises registered by the government. Because non-standard employment also faces the same instability and high mobility in informal sector employment, it is usually discussed in informal employment, but in essence there is still an essential difference between the two. Nonstandard employment mainly involves employment standard, not survival problem. As a result, this paper only discusses the employment in the informal sector of tourism, and select five typical urban scenic spots in Fuzhou (Three Lanes and Seven Alleys; Drum Mountain; Luoyuan Bay Marine World; Guian Theme Park; Pingtan Island) as a case study. Sanfang Qixiang, literally Three Lanes and Seven Alleys, is a historic and cultural area in the city of Fuzhou. Covering a total area of 0.38 square kilometers $(0.15 \mathrm{sq} \mathrm{mi})$, it is celebrated as an architectural museum of Ming and Qing Dynasty buildings. Drum Mountain is located 8 kilometers away from east of Fuzhou, stretching over 1,890 hectares. Its highest peak is 919 meters above sea level. According to legend, there sits at the mountaintop a huge stone flat as a drum that produces drum-beating sound whenever it rains. Hence it is named Drum Mountain. The Ocean World has been successfully listed as Luoyuanwan's first-aid aquatic station for aquatic wild animals, and will become the science education base for teenagers in Fujian Province. Moreover, it is striving to build itself into a 5Alevel tourist attraction. Pingtan Island is an island of Fuzhou off the east coast of mainland Asia in Pingtan County, Fujian Province, China (PRC), south of the complex estuary of the Min River. It is the largest island in Fujian and the fifth-largest island administered by the People's Republic of China. This paper carried out a survey from February 27 to March 23 in 2021, which involved the types, scale, spatial and temporal distribution of the tourism informal sector, and carried out a questionnaire survey according to the scale quota. Because the tourism informal employment group is small, and the ability to interpret the questionnaire and the response rate are relatively low, this paper adopts a convenient and snowball sampling 
method. All the employed people in 5 scenic spots were interviewed. There are 175 interviewees responded to the survey, excluding 24 invalid questionnaires, and finally got 151 valid questionnaires. The effective rate was 86.3. The demographic is shown in "Table 1 ".

Table 1. The demographic characteristics of the respondents

\begin{tabular}{|c|c|c|c|c|c|}
\hline Category & Frequencies & Percentages & Category & Frequencies & Percentages \\
\hline \multicolumn{3}{|c|}{ Personal monthly income (yuan) } & \multicolumn{3}{|l|}{ Gender } \\
\hline $\begin{array}{l}\leq 1000 \\
1001 \sim 2000 \\
2001 \sim 3000 \\
3001 \sim 4000 \\
4001 \sim 5000 \\
\geq 5001\end{array}$ & $\begin{array}{l}25 \\
45 \\
34 \\
22 \\
14 \\
11\end{array}$ & $\begin{array}{l}16.5 \\
29.8 \\
22.5 \\
14.6 \\
9.3 \\
7.3\end{array}$ & $\begin{array}{l}\text { Male } \\
\text { Female }\end{array}$ & $\begin{array}{l}71 \\
80\end{array}$ & $\begin{array}{l}47.0 \\
53.0\end{array}$ \\
\hline Education & & & Age & & \\
\hline \begin{tabular}{l} 
Primary school \\
level \\
Junior high \\
school level \\
Senior high \\
school level \\
Undergraduate \\
level \\
\multicolumn{2}{l}{ Years of working }
\end{tabular} & $\begin{array}{l}35 \\
43 \\
44 \\
29\end{array}$ & $\begin{array}{l}23.2 \\
28.5 \\
29.1 \\
19.2\end{array}$ & $\begin{array}{l}16 \sim 25 \\
26 \sim 35 \\
36 \sim 45 \\
46 \sim 60 \\
\geq 61\end{array}$ & $\begin{array}{l}36 \\
43 \\
38 \\
27 \\
7\end{array}$ & $\begin{array}{l}23.8 \\
28.5 \\
25.2 \\
17.9 \\
4.6\end{array}$ \\
\hline $\begin{array}{l}\leq 0.5 \\
0.5 \sim 1 \\
1 \sim 3 \\
4 \sim 6 \\
7 \sim 9 \\
\geq 10\end{array}$ & $\begin{array}{l}25 \\
35 \\
49 \\
17 \\
9 \\
16\end{array}$ & $\begin{array}{l}16.5 \\
23.2 \\
32.5 \\
11.3 \\
6.0 \\
10.6\end{array}$ & $\begin{array}{l}\text { Full time } \\
\text { Part time } \\
\text { Random time }\end{array}$ & $\begin{array}{l}101 \\
24 \\
26\end{array}$ & $\begin{array}{l}66.9 \\
15.9 \\
17.2\end{array}$ \\
\hline & & & $\begin{array}{l}\text { Scenic spots } \\
3 \text { Lanes } 7 \text { Alleys } \\
\text { Drum Mountain } \\
\text { Luoyuan Marine } \\
\text { Guian Theme } \\
\text { Pingtan Island } \\
\end{array}$ & $\begin{array}{l}33 \\
33 \\
33 \\
22 \\
30\end{array}$ & $\begin{array}{l}21.9 \\
21.9 \\
21.9 \\
14.6 \\
19.9 \\
\end{array}$ \\
\hline
\end{tabular}

In addition to the subjective well-being scale, the questionnaire also includes an overall wellbeing evaluation and two aspects of the questions: one is about demographic characteristics, such as gender, age, education, personal monthly income, and the other is about the status of employment, such as the scenic area, working years, employment status, employment investment and daily working hours. Based on the SPSS 19.0, this paper first uses principal component analysis to extract a number of specific areas of quality of life from 31 items, and then carries-by-step multivariate regression analysis between these areas of life and overall well-being of life. In order to understand the main components of the quality of life of non- employment and its interpretation. This paper further uses one-way ANOVA to compare whether there are significant statistical differences in population characteristics and employment status in the main areas of quality of life.

\section{RESEARCH FINDING}

\subsection{Quality of Life Assessment Score}

In the reliability test of 31 items in this questionnaire, Cronbach's alpha is 0.884, with a high reliability. The KMO value of factor analysis is 0.773 , which is close to the level of 1 , which indicates that the sample size is sufficient, and the approximate chi-square value of Bartlett's spherical test is 1776.240 , and the degree of freedom is 465 , which reaches 0.05 significant level $(\mathrm{p}=0.00<0.05)$, which indicates that the sample is suitable for factor analysis. By using the maximum variance method (varimax) rotation for principal component analysis, 10 areas of quality of life were extracted from 31 items, and the cumulative interpretation reached 67.376, which had good explanatory power ("Table 2"). The 10 quality of life areas are named as "family life" respectively, which is the first public factor, including three family centered quality of life items, reflecting the level of family life quality of the employed. "Leisure and entertainment" refer to four items related to the leisure time, leisure conditions, leisure behaviour and leisure expenditure of the employed, reflecting the characteristics of leisure and entertainment of the employed improve the situation. "Working condition" includes working intensity, environment and freedom 4 items related to the degree of 
employment and their own health status, reflecting condition. "Job prospects" include job stability. the employment. The improvement of working

Table 2. Importance of the structure matrix and factor analysis

\begin{tabular}{|c|c|c|c|c|}
\hline Factors & Factor loading & EV & $\begin{array}{l}\text { Cumulated } \\
\text { explained }\end{array}$ & variance \\
\hline Family life (FL) & & 2.67 & 8.613 & \\
\hline Better family relationship & 0.803 & & & \\
\hline Higher well-being of family & 0.732 & & & \\
\hline More time for family life & 0.728 & & & \\
\hline Leisure and entertainment (LE) & & 2.455 & 16.531 & \\
\hline More frequency of leisure & 0.821 & & & \\
\hline More time for leisure & 0.682 & & & \\
\hline More expenditure for leisure & 0.681 & & & \\
\hline Well-equipped facilities of leisure & 0.63 & & & \\
\hline Work condition (WC) & & 2.412 & 24.312 & \\
\hline Lower work intensity & 0.748 & & & \\
\hline Better work environment & 0.735 & & & \\
\hline Greater latitude in work & 0.604 & & & \\
\hline Better physical health & 0.481 & & & \\
\hline Work prospects (WP) & & 2.147 & 31.239 & \\
\hline Higher job stabilization & 0.827 & & & \\
\hline More hopeful prospect of work & 0.741 & & & \\
\hline Higher income of work & 0.599 & & & \\
\hline Capability development (CD) & & 2.135 & 38.126 & \\
\hline Stronger ability of learning & 0.809 & & & \\
\hline Better ability of communication & 0.591 & & & \\
\hline Better information capturing ability & 0.524 & & & \\
\hline More opportunities for work development & 0.512 & & & \\
\hline Social interaction (SI) & & 2.123 & 44.975 & \\
\hline Wider network of social communication & 0.738 & & & \\
\hline Closer relations with colleague & 0.703 & & & \\
\hline More time with friends & 0.562 & & & \\
\hline Consumption and safety (CS) & & 1.969 & 51.326 & \\
\hline Factors & Factor loading & EV & $\begin{array}{l}\text { Cumulated } \\
\text { explained }\end{array}$ & variance \\
\hline Higher consumption ability & 0.677 & & & \\
\hline Better public security environment & 0.625 & & & \\
\hline More reasonable price of necessity & 0.583 & & & \\
\hline Mental health and medic (MM) & & 1.856 & 57.313 & \\
\hline Higher price endurance of medic & 0.767 & & & \\
\hline Better mental health & 0.671 & & & \\
\hline Good communication \& coordination skill & 0.67 & & & \\
\hline Host-guest interaction (HG) & & 1.64 & 62.603 & \\
\hline More communicate with visitors & 0.712 & & & \\
\hline Physical well-being (PW) & & 1.48 & 67.376 & \\
\hline Lower cost of necessity & 0.671 & & & \\
\hline Better living facilities & 0.614 & & & \\
\hline More reasonable price of house & 0.501 & & & \\
\hline
\end{tabular}


Gender, expected future and income level are three items, which reflect the employment demand for work. Make the expectation of future development. "Ability development" refers to learning ability and gap. In order to explain the employment situation, four items, namely, communication ability, information acquisition ability and opportunity, are selected. The ability development of the students. "Social communication" includes three topics, including colleagues, friends and family, and social networks, which reflect the social situation of employed people. "Consumption and security" include consumption capacity, consumption security, consumption price and other three items, reflecting the consumption status of employed people. "Mental health and medical treatment" involve medical price tolerance, mental state and coordination ability three items, reflecting the individual mental medical condition. "Subjectobject communication" has only one item, reflecting the level of subject-object interaction. "Living conditions" include the expenditure of necessities, living facilities and housing and other important conditions, indicating the level of improvement in the living conditions of employed people.

"Table 3" descriptive statistics show that, between $0.951 \sim 1.210$, It shows that the evaluation scores of tourism informal employment in various main areas of quality of life are relatively concentrated. Among them, Mean=5.550, This was followed by competency development

Table 3. Quality of life domain scores
(Mean=4.702), work status (Mean=4.662) and social communication (Mean=4.530), while work prospects $\quad($ Mean=4.042), living conditions $($ Mean=4.040) and leisure and entertainment (Mean=3.776) scored lower. This shows that, on the one hand, tourism informal employment generally has a direct positive impact on the subject-object communication, ability development, work situation and social communication of the employed; on the other hand, engaging in informal employment cannot better improve the leisure, entertainment and living conditions of the employed, and the expectation of work prospects is generally low, which is closely related to the characteristics of informal employment. Unlike ordinary residents, informal workers in a sense sacrifice their leisure and entertainment opportunities to meet the leisure needs of others. At this time, tourism development cannot improve their leisure and entertainment situation. In general, the assessment scores of employed people in most fields are not high (except for subjective and objective communication, the average value of other fields is less than 5), and the well-being is.

\begin{tabular}{lll}
\hline QOL domains & Mean & SD \\
\hline FL & 4.4 & 1.21 \\
\hline LE & 3.776 & 1.179 \\
\hline WC & 4.662 & 1.006 \\
\hline WP & 4.042 & 1.189 \\
\hline CD & 4.702 & 1.049 \\
\hline SI & 4.53 & 1.096 \\
\hline CS & 4.327 & 1.019 \\
\hline MM & 4.49 & 0.963 \\
\hline HG & 5.55 & 1.153 \\
\hline PW & 4.04 & 0.951
\end{tabular}




\subsection{Main Areas of Quality of Life for Employed Persons}

Taking 10 life fields as predictive variables and "overall life well-being" as dependent variables, the general linear stepwise multiple regression is carried out. The results are shown in Table 4. According to Table 4, in the 10 areas of quality of life, there are 8 variables with significant predictive power for the overall well-being of the employed, in order," leisure and entertainment "," work prospect "," family life "," work condition "," social communication "," consumption and security "," ability development "and" living conditions ". A multivariate correlation coefficient $(\mathrm{R})$ of 0.778 for eight quality of life areas, Adjusted coefficient of determination (R2) is 0.583 , the $F$ value of the final regression model integrity test is $27.265(\mathrm{p}=0.000<0.001)$. Therefore, 8 public factors can effectively explain $58.3 \%$ of the total happiness of life. Mental health and medical treatment and subject-object communication were excluded.

From the point of view of standardized regression coefficient, all $\beta$ coefficients are positive, indicating that 8 fields have a positive effect on overall well-being of life. "Leisure and entertainment" have the best predictive power, the interpretation reached $16.3 \%$, indicating that as ordinary residents, informal workers also pay great attention to leisure and entertainment. The improvement of leisure and entertainment happiness will significantly improve the overall happiness of life. However, the leisure and entertainment well-being of tourism informal employment is at a low level (Table 3). The rest are "work prospects", "family life" and "work

Table 4. Stepwise multiple regression analysis of predicting total life satisfaction among tourism informal employees

\begin{tabular}{lllllll}
\hline Domains & $\mathrm{R}$ & $\mathrm{R} 2$ & $\mathrm{~F}$ value & $\Delta \mathrm{F}$ & $\mathrm{B}$ & $\beta$ \\
\hline LE & 0.411 & 0.163 & $30.238^{* *}$ & $30.238^{* *}$ & 0.435 & 0.411 \\
\hline WP & 0.551 & 0.294 & $32.184^{* *}$ & $28.542^{* *}$ & 0.388 & 0.367 \\
\hline FL & 0.638 & 0.395 & $33.621^{* *}$ & $25.736^{* *}$ & 0.341 & 0.322 \\
\hline WC & 0.693 & 0.467 & $33.816^{* *}$ & $20.810^{* *}$ & 0.288 & 0.272 \\
\hline SI & 0.729 & 0.516 & $32.936^{\star *}$ & $15.751^{* *}$ & 0.239 & 0.226 \\
\hline CS & 0.752 & 0.547 & $31.152^{\star *}$ & $10.941^{*}$ & 0.193 & 0.182 \\
\hline CD & 0.768 & 0.57 & $29.398^{* *}$ & $8.778^{*}$ & 0.168 & 0.159 \\
\hline PW & 0.778 & 0.583 & $27.265^{* *}$ & $5.647^{*}$ & 0.133 & 0.125 \\
\hline & & & & & $\mathrm{p}<0.05 ; * *<<0.001$
\end{tabular}

conditions ", The amounts explained were 13.1 per cent ,10.1 per cent and 7.2 per cent, well-being in these three areas is at a moderate level (Table 3). The combined interpretation of the four areas with relatively low happiness scores was $46.7 \%$, As a result, the overall well-being of tourism informal employment is at a moderate level. In addition, Higher well-being of the ability to develop and the previous research on ordinary residents of the field of living conditions but in the tourism informal employment of the overall well-being of the interpretation of the weak. The assessment of living conditions of employed persons is generally low, and the limited improvements that informal employment in tourism can bring, it is difficult to have a greater impact on their overall well-being of life. 


\subsection{Differences in Demographic Characteristics and Employment Status in the Main Areas of Quality of Life of Employed Persons}

A single factor ANOVA was used to analyze the population characteristics (age, education, personal monthly income) and employment status (working years, working hours, investment, employment status, scenic spots), to compare whether there are significant statistical differences in the above factors in the eight areas of quality of life, and to further adopt the Tukey method for subsequent analysis. The results are shown in "Table 5".

Table 5. Subject well-being domains differences by demographics and working conditions

\begin{tabular}{llll}
\hline Category & QOL domains & $F$ value & $P$ value \\
\hline Age & CD & 4.786 & 0.001 \\
Education & CD & 7.789 & 0 \\
Work hours & FL & 5.319 & 0.001 \\
Investment & CD & 5.794 & 0 \\
Work status & CD & 4.789 & 0.01 \\
Scenic spots & LE & 5.057 & 0.001 \\
& WC & 3.094 & 0.018 \\
& SI & 3.377 & 0.011 \\
& CD & 2.461 & 0.048 \\
\hline
\end{tabular}

According to Table 5, there is little difference in happiness in most areas of quality of life between tourism informal employment with different sociodemographic characteristics and employment conditions. This shows that the quality of life of informal employment in tourism has a high homogeneity, and most people's happiness is concentrated in the middle level. There are no significant statistical differences in the number of employed persons of different genders, individual monthly income and years of work, even in various areas of quality of life. This is in line with previous results on significant differences in the quality of life of the inhabitants of tourist destinations. This is because: on the one hand, 92.7 per cent of informal workers are low- and middle-income groups with a monthly income of less than $\$ 5,000$ (table 1). The income gap between individuals is small; on the other hand, low entry threshold for informal employment, low exit costs, liquidity, 72.3 per cent of employed persons have worked for less than three years (Table 1), and longer working years cannot accumulate enough advantages to significantly improve the quality of life.

There are significant statistical differences in the field of quality of life ability development among the employed persons of different ages, academic qualifications, scenic spots, employment investment and employment status. The happiness of ability development is significantly lower than that of other age groups; primary school and below are significantly lower than other higher education groups; low employment investment groups are significantly lower than high employment investment groups. This is due to the fact that, compared to younger groups, those over the age of 60 are engaged in informal employment mainly for the purpose of subsidizing their families, improving their lives or killing time, and do not value capacity development, which is difficult to use to improve the quality of life. Compared with other groups, primary school and below, low employment investment group and Luoyuan Bay group are mainly mobile snack vendors and candle sellers. They have simple ability and narrow career prospects, so they have little progress in ability development. At the same time, they have small investment, low risk, low emphasis on ability improvement and low overall happiness. Full-time group income mainly comes from tourism informal employment, the overall income level is lower than part-time group (and other income). Because parttime groups have various jobs, diverse abilities, positive demands for career development, high attention to ability development, ability development is very important to the improvement of their quality of life, so their happiness in ability development is higher. 


\section{CONCLUSIONS AND DISCUSSIONS}

In this paper ,151 non-formal workers from 5 scenic spots in Fuzhou are taken as samples. Principal component analysis and step-by-step multiple regression show that the quality of life of non-formal workers can be divided into 10 areas, and the areas that can better explain their overall well-being of life are leisure and entertainment, work prospects, family life, work status, social communication, consumption and safety, ability development and living conditions. Obviously, the composition of the quality of life of the informal employment of tourism is different from that of the ordinary residents. The quality of life of the residents of tourist destinations studied by Andereck is closely related to the fields of leisure and entertainment, community welfare, urban problems, lifestyle and community identity, and less to the field of economic development, including the main indicators of work status and work prospects. Moreover, the results of this paper are also different from those of such as Kim, Guo Yingzhi (2007) and Moscardo and other (Moscardo et al., 2013). In the past, the best explanatory field of leisure and entertainment was generally low. Tourism informal employment intensity, indecent, leisure and entertainment time is less, with its service of tourists form a strong contrast, it is easy to reduce happiness because of the contrast effect. In addition, the quality of life of informal workers is more sensitive to changes in working conditions and prospects, and their family life is also deeply affected by informal work, so it has a higher explanatory power. Therefore, the residents of tourist destination are not homogeneous groups, and the residents engaged in informal employment in tourism have great differences in their quality of life and their interpretation level. In the future tourism development on the quality of life of residents, need to be treated differently.

This study further shows that there is little difference in well-being in most areas of quality of life between employment with different social and demographic characteristics and employment conditions. There are no significant statistical differences in the number of employed persons of different genders, individual monthly income and years of work, even in various areas of quality of life. On the one hand, the overall well-being of tourism informal employment is highly concentrated, the difference between individuals is small, and is at a medium level; on the other hand, the difference of population characteristics and employment status has little effect on their quality of life.

The tourism informal employment people belong to the homogeneous group in the quality of life, and the improvement of individual factors makes the quality of life significantly higher than that of other individuals. Therefore, ways to improve the quality of life of non-regular workers in tourism can only be through group-level measures that affect their main areas of quality of life. Improving the working conditions of informal workers, leading informal work to formalization, improving the income level and stability of practitioners, and reducing the working hours of employed people will significantly improve the quality of life of this group. In addition, from the observation of informal workers in five scenic spots, encouraging community residents to participate in informal employment, thus reducing the proportion of foreign participants will effectively improve the quality of life of employed people.

\section{AUTHORS' CONTRIBUTIONS} $\mathrm{Xu}$.

This paper is independently completed by Jiajia

\section{REFERENCES}

[1] Ashley, C., \& Mitchell, J. (2010). Tourism and poverty reduction. Pathways to Prosperity. London: Earthscan.

[2] Allen, L. R. (2018). Benefits of Leisure Attributes to Community Satisfaction. Journal of leisure research, 22(2), 183-196. doi:10.1080/00222216.1990.11969824

[3] Andereck, K. L., \& Nyaupane, G. P. (2010). Exploring the Nature of Tourism and Quality of Life Perceptions among Residents. Journal of Travel Research, 50(3), 248-260. doi:10.1177/0047287510362918

[4] Ap, J. (1992). Residents' perceptions on tourism impacts. Annals of tourism research, 19(4),

665-600. doi:https://doi.org/10.1016/01607383(92)90060-3

[5] Bauer, R. A. (1960). Consumer behavior as risk taking. Chicago, IL, 384-398. 
[6] Bimonte, S., \& Faralla, V. (2014). Happiness and nature-based vacations. Annals of tourism research, $\quad 46, \quad 176-178$. doi:10.1016/j.annals.2014.02.002

[7] Boonsiritomachai, W., \& Phonthanukitithaworn, C. (2019). Residents' support for sports events tourism development in Beach City: The role of community's participation and tourism impacts. Sage Open, 9(2), 2158244019843417.

[8] Buzinde, C. N., Kalavar, J. M., \& Melubo, K. (2014). Tourism and community well-being: The case of the Maasai in Tanzania. Annals of tourism research, 44, 20-35. doi:10.1016/j.annals.2013.08.010

[9] Caunt, B. S., Franklin, J., Brodaty, N. E., \& Brodaty, H. (2012). Exploring the Causes of Subjective Well-Being: A Content Analysis of Peoples' Recipes for Long-Term Happiness. Journal of Happiness Studies, 14(2), 475-499. doi:10.1007/s10902-012-9339-1

[10] J.E.Brougham, R. W. B. (1981). A segmentation analysis of resident attitudes to the social impact of tourism. Annals of tourism research, 8(4), 569-590. doi:https://doi.org/10.1016/01607383(81)90042-6

[11] Kim, K., Uysal, M., \& Sirgy, M. J. (2013). How does tourism in a community impact the quality of life of community residents? Tourism Management, 36, 527-540. doi:10.1016/j.tourman.2012.09.005

[12] Lankford, S. V. (2016). Attitudes and Perceptions Toward Tourism and Rural Regional Development. Journal of Travel Research, 32(3), 35-43. doi:10.1177/004728759403200306

[13] Liang, Z.-X., \& Hui, T.-K. (2016). Residents' quality of life and attitudes toward tourism development in China. Tourism Management, 57, 56-67. doi:10.1016/j.tourman.2016.05.001

[14] Marcouiller, D. W. (2016). Toward Integrative Tourism Planning in Rural America. Journal of Planning Literature, 11(3), 337-357. doi:10.1177/088541229701100306

[15] Maslow, A. H. (1959). New knowledge in human values.
[16] McCabe, S., \& Johnson, S. (2013). The Happiness Factor in Tourism: Subjective Well-Being and Social Tourism. Annals of tourism research, 41, 42-65. doi:10.1016/j.annals.2012.12.001

[17] Meier, A., \& Schäfer, S. (2018). The positive side of social comparison on social network sites: How envy can drive inspiration on Instagram. Cyberpsychology, Behavior, and Social Networking, 21(7), 411-417.

[18] Mohotti, C., Jayawardena, C. C., \& Teare, R. (2013). Responding to the tourism industry training and human resource challenges in Sri Lanka. Worldwide Hospitality and Tourism Themes, 5(5), 456-463.

[19] Mohseni, S., Jayashree, S., Rezaei, S., Kasim, A., \& Okumus, F. (2018). Attracting tourists to travel companies' websites: the structural relationship between website brand, personal value, shopping experience, perceived risk and purchase intention. Current Issues in Tourism, 21(6), 616-645.

[20] Moscardo, G., Konovalov, E., Murphy, L., \& McGehee, N. (2013). Mobilities, community well-being and sustainable tourism. Journal of Sustainable Tourism, 21(4), 532-556. doi:10.1080/09669582.2013.785556

[21] Nawijn, J., \& Mitas, O. (2011). Resident Attitudes to Tourism and Their Effect on Subjective Well-Being. Journal of Travel Research, 51(5), 531-541. doi:10.1177/0047287511426482

[22] R.Hoy, F. J. B. D. (1980). The perceived impact of tourism by residents a case study in Santa Marta, Colombia. Annals of tourism research, 7(1), 83-101. doi:https://doi.org/10.1016/S01607383(80)80008-9

[23] Stylidis, D., Biran, A., Sit, J., \& Szivas, E. M. (2014). Residents' support for tourism development: The role of residents' place image and perceived tourism impacts. Tourism Management, 45, 260-274. doi:10.1016/j.tourman.2014.05.006

[24] Ulleberg, P., \& Rundmo, T. (2003). Personality, attitudes and risk perception as predictors of risky driving behaviour among young drivers. Safety science, 41(5), 427-443. 
[25] Vittersø, J., Oelmann, H. I., \& Wang, A. L. (2007). Life Satisfaction is not a Balanced Estimator of the Good Life: Evidence from Reaction Time Measures and Self-Reported Emotions. Journal of Happiness Studies, 10(1), 1-17. doi:10.1007/s10902-007-9058-1

[26] Westman, M., \& Eden, D. (1997). Effects of a respite from work on burnout: vacation relief and fade-out. Journal of Applied Psychology, 82(4), 516. 